\title{
An Ecosystem of Equity in the Era of COVID-19:Considerations for Creating Inclusive Teaching and Learning Environments
}

\author{
Starlette Sharp ${ }^{1}$, Jonathan McCausland ${ }^{1}$, Leandra Cate ${ }^{1}$, Charlita Woodruff-White ${ }^{2}$, and \\ Gregory Kelly ${ }^{1}$ \\ ${ }^{1}$ Pennsylvania State University \\ ${ }^{2}$ Morgan State University
}

June 17,2020

\begin{abstract}
Distance learning has been a means to provide an education to those who are unable to participate in on-campus, face-to face classes. Teams of instructional design specialists that focus on online education put significant effort into course development. This planned process is very different from emergency remote education in response to a crisis. In early 2020, it was discovered that an extremely contagious respiratory illness termed COVID-19 had spread to every corner of the earth. As of mid-March 2020, the need to transition from face-to-face classroom instruction to exclusively online education landed on the doorstep of America's universities. COVID-19 has catalyzed a transition in the ecology of American education for all students, but especially the underserved and minoritized. Ecology, by definition, is concerned with the interactions of an organism and its environment. The circumstances of the pandemic have caused vast and rapid change in both the internal and external environments of the organisms (e.g., students) and the systems in which they reside (e.g., U. S. educational systems). The purpose of this paper is to provide some considerations for instructors who find themselves "thrown into teaching remotely," and help them think about how best to create sustainable systems, broaden participation and build capacity in a more equitable and inclusive manner.
\end{abstract}

\section{An Ecosystem of Equity in the Era of COVID-19:}

\section{Considerations for Creating Inclusive Teaching and Learning Environments}

There is no such thing as a single-issue struggle because we do not live single-issue lives. - Audre Lorde (Sister Outsider, 1984)

In late December 2019 the world became aware of a strange form of acute respiratory distress discovered by hospital physicians in Wuhan, China. Within 90-days this extremely contagious respiratory illness, now known as COVID-19, invaded almost every country on earth and was named by the World Health Organization (WHO) as the first worldwide health pandemic since the peak of human immunodeficiency virus (HIV) (MacArthur, 2020). As of June 1, 2020, more than 395,000 people's deaths were to blame on the virus. Daily life came to a simultaneous grinding halt for everyone around the world. People from all corners of the earth attempted to implement modifications and adaptations for all facets of daily life as the new rule of the world was "sheltering in place."

Sheltering in place was described as a WHO and Center for Disease Control (CDC) best practice and government enforced method of mandating everyone to remain inside their homes. A few exceptions were made for leaving the house for food and medical/pharmaceutical care. The idea was to limit the amount of person-to-person contact of each individual. Doing so would isolate people to their own personal spaces, but also quarantine those infected with the virus, whether they were symptomatic or asymptomatic carriers. This policy promptly caused problems for those that reside in high density and communal living situations. One 
such place that is both high density and communal is the thousands of residence halls on college campuses all over the world.

These immediate transformations were disruptive to all "normal" life but posed distinct challenges to higher education. Effective immediately, campuses world-wide were closed to student-residents, face-to-face instruction and all non-essential employees. Instructors, who were in some cases a third of the way through the semester, faced a multitude of obstacles that all needed immediate solutions. And suddenly, a perfect storm of educational and economic chaos formed. These challenges manifested in ways foreseen and unforeseen and catalyzed undeniable hardship for many students, particularly those of low socio-economic status or other marginalized demographics. This kind of institutional change has not been seen since the landmark Supreme court case Brown $v$. Board in 1954 making racial segregation in schools unconstitutional. That kind of change took decades and the changes induced by COVID-19 were felt overnight. In order to persist and complete the semester, students were asked to "return home and continue their studies from there via remote instruction." Only later during the pandemic would we come to know the degree of assumptions made in that statement.

\section{Exaggerating Existing Inequality: An Introduction}

Before a global pandemic swept through the U.S. and brought about unprecedented social and economic change, there were deep and deepening inequities of race, class, and gender. As COVID-19 prompted universities to swiftly shutter their campuses and switch to remote instruction, there were already students who were struggling with homelessness, discrimination, poverty, food insecurity, and mental illness (figure 1). This health crisis exaggerated these existing disparities as it made them more visible. Drawing upon the notion of an ecosystem as a framework for understanding, the analysis presented in this study aims to generate creative solutions to problems that are inherent to US higher education outside the context of a global crisis.

In order to propose solutions, we will provide insight for instructors, administrators, and researchers into some of the societal determinates, (e.g., the experiences and identities students bring with them to class), that affect the teaching and learning of students during crisis remote instruction. We also will provide tangible and practical suggestions that can be implemented, hopefully, without additional cost or infrastructure. Being aware of some of the difficult circumstances that students endure can assist us with better modifying our teaching practices for increased equity and inclusion. Small changes in instructor acknowledgment, rhetoric, empathy, and practices can have large learning implications over time. Though one class will not change the entire educational system, we do have the power to lead by example, starting right where we are, one student at a time.

\section{The Landscape}

The concept of receiving an education from an institution that one is geographically distant from is not new. In various ways distance learning has been in operation since1858 (Willis, 1994, Anderson, 1998, Sumner, 2000). Certainly, distance education has evolved over the years, from correspondence courses that mainly utilized the postal service for delivery to online education being delivered through the worldwide web. The worldwide web has greatly expanding the presence of distance learning. One of the main factors that makes online education attractive is the portability and ability to be accessed from all over the world. Online education as a platform for learning has allowed students that are working full-time, active military/deployed or have other responsibilities that prevent them from attending in class sessions to matriculate through their chosen curriculum (Willis, 1994). This type of instruction is very different from the largely unplanned, emergency induced remote instruction implemented this year to ensure students' progress towards a degree. Therefore, it is important that crisis education delivery be separated from intentionally structured and thoroughly planned online education.

The planning of typical online instruction is what separates it from emergency online instruction. Normally, for courses to be delivered (online or in person) during a typical fall semester, the previous months are spent organizing which courses will be taught, deciding which classroom has the appropriate equipment and 
seating capacity, and managing what time the course should be offered (Anderson, 1998). If a class is to be taught online, a team of online education development specialists (e.g., course strategy, content, outcomes and assessment) come together to build the course.

In contrast, during the COVID-19 pandemic, most institutions of higher education who had already been in session for 4-6 weeks changed course. Without the benefit of advanced planning, foresight or fundraising, colleges converted all face-to-face courses to remote instruction through various online delivery systems. Prior to the COVID-19 pandemic, according to the Babson Survey Research Group (Allen, 2017), 33 percent of college students were taking at least one course online. Currently, due to the COVID-19 pandemic, 100 percent of college students are taking 100 percent of their courses online. This modified method of course delivery was a colossal undertaking and accomplished in an unprecedented time frame, little more than a week. Universities and institutions of higher learning are to be applauded for following through on their commitment to offering and delivering the courses that they began in January despite a world-wide health crisis of incredible proportions.

Even with the hard work and effort put into moving courses into a remote format, problems arose. While not entirely new, instructors were left to grapple with all the issues, social determinants and educational disparities that determine how well students learn. COVID-19 forced instructors to teach under extreme circumstances. As a result, our educational ecosystem has been put into further disarray, highlighting how inequitable and exclusive higher education is. Institutions of higher education are not accomplishing the lofty goals to which they aspire. For centuries, the United States has been unwilling to face the truth about the systemic institutionalized inequities that are perpetuated generation after generation of American students.

Education has never occurred in a vacuum and its reach is only as far as the unmitigated societal determinants that act as barriers to students (e.g. homelessness, poverty, unemployment, food insecurity, poor healthcare, unchecked mental illness, sexual orientation, race, ethnicity and immigrant status). Higher education has long been touted as the key to the middle class and a requirement to become upwardly mobile in American society. The consistent exclusion, persistent undermining and continuous marginalization of persons that want to become upwardly mobile in the United States has led to the current economic and educational crises the country faces. Equity in the US education system has been unattained throughout its history. COVID-19 brought to light some of the pronounced inequalities manifested during remote teaching; these inequalities intensified the existing reality of higher education in the US. These conditions have left instructors in a difficult position. As they endeavor to teach their courses remotely and actively engage students with the material, they are struggling to comprehend and equitably accommodate many of their students' unfortunate circumstances.

\section{The Higher Education Ecosystem}

The ecosystem is a cornerstone of understanding relationships between organisms and their environment. Ecosystems are made up of interacting organisms and the physical environment. Higher education is no different. From instructors to graduate students, administrators and administrative assistants, all the way to physical plant workers and students, higher education is a menagerie of different actors. Beyond the people, institutions of higher learning are made of material entities like dorms, classrooms, office spaces, student unions, health services, and numerous centers that perform a variety of functions. These systems are interconnected through technologies, modes of communication, cultural histories and traditions, and knowledge recognized as legitimate across the academic disciplines. Like natural ecosystems, the higher education ecosystem relies on each factor to operate at full capacity or the system will be less resilient or even collapse all together.

One factor that can result in the destruction of an ecosystem in nature is the introduction of an invasive species. In our case, COVID-19 is the invasive species. It is introducing new pressures that must be responded to. It is also highlighting the vulnerabilities that already existed in our ecosystem of higher education. In our ecosystem the goal is to help students learn; therefore, when elements of our ecosystem falter, the potential for student learning decreases. Therefore, it is our job to identify the weaknesses in our ecosystem and find 
new, creative ways to help our cornerstone, the students, thrive. Without them and their learning, our ecosystem will cease to exist.

\section{The Producers}

A productive online ecology class starts with the faculty being honest and vulnerable about their own understandings of the students and their circumstances. Through such understanding, they can create an environment where shame has no place and difference is acknowledged and valued.

Instructors in charge are the producers of our ecosystem. They set the mood, tone, and atmosphere for students for the entire semester of the course. Nothing can survive the ecosystem without the producers. In this transition from face-to-face instruction, the producers must be intentional and deliberate. Instructors must embrace the fact that good teaching can transport students away from wherever they are to where instructors want them to be. Now more than ever it is imperative that our online teaching practices be led with vulnerability and empathy (hooks, 1994, Brown, 2018). We must acknowledge the environmental and circumstantial differences while welcoming them. During these difficult times it is important that we remember that our students are individuals who live diverse and complicated lives. There are those that only need consistency and stability in their teaching environment, while others may require extra support.

Moreover, it is not just about the instructors' academic and content language. Instructor non-content talk is more vital than ever in establishing an engaged and inviting "online classroom" culture. Research by the Tanner lab shows that instructor non-content talk impacts (a) building the instructor-student relationship, (b) establishing the classroom culture, (c) pedagogical choices, (d) provides avenues for sharing personal experiences, and 5) unmasking science (Seidel, 2015). All these elements were important in the face-to-face classroom setting, but are even more so during crises remote instruction and online teaching. Non-content talk can break down barriers and allow instructors to connect with students as humans, inspire students to dig deeper and persist and it also decreases the feelings of social and emotional distance between the instructor and students (Mehrabian, 1971). Limiting this perceived distance in the context of sudden and dramatic isolation can help students feel more connected and motivated (Gorham, 1992). Teaching is inherently relational; therefore, it is imperative that instructors engage in politicized caring (McKinney de Royston, 2017 , hooks, 1994) that connects with students in robust ways that does not ignore the larger sociocultural contexts in which they are currently living (figure 2).

\section{More than just disciplinary knowledge: The Classroom Ecosystem}

In ecosystems, organisms have relationships with one another. In some cases, like in the case of an instructorstudent relationship, both organisms receive a mutual benefit (hooks, 1994). Traditionally, in higher education, the students receive knowledge while the instructor learns from and with the students as they engage in the learning process. During this unprecedented time, we must still provide students with the skills and knowledge needed to succeed in the future. Yet, given the haphazard manner in which courses were transitioned to remote learning, we must find other ways to ensure students are getting what they need from a course. This should include modeling empathy and care.

One way to do this is to check-in with students. Depending on the size of the class this can take multiple forms ranging from class polls/surveys to literally sharing verbally. Asking if everyone is well and safe, allows for you (the instructor) to monitor each student's personal wellbeing. You can even ask them what they need and what they can give on any given day (Whitney, 2020). If they indicate that they are not well, you can refer them to the appropriate university resources. You can also express to the students any frustrations or complications you are experiencing due to the circumstances as an example of vulnerability. When you are the role model for discussing difficult topics and when you model bravery it communicates that, whatever the student is feeling, their feelings are valid, and they should not be ashamed of them. Hopefully, this signaling to the students that during difficult times everyone is struggling to make sense of things. Additionally, the start of class may be a good time to let students know how they can connect with on-campus resources. Providing the phone number and/or website for resources on the lecture slide or class website would be helpful. Simply by providing these resources to students you are signally that they should take advantage 
of what is available. That is important because university services are still available to students remotely. This endorsement of services publicly helps remove the negative stigma of accessing these resources.

\section{A Changing Environment: The Importance of Stability}

The beauty in the ecology of the campus community is that it is the same for all its inhabitants (albeit experienced differently)

In ecosystems, environments are not only made up of organism, but they also include abiotic factors necessary for survival. In our ecosystem analysis, we imagine the various services provided by institutions as these abiotic factors. In our ecosystems of higher education, different participants, including teachers and learners, share the organizational context and a network of mutual influence, within which there are differences of needs, resources, and responsibilities. Due to the current COVID-19 pandemic, consistent messaging through news and other media outlets is that, "We're in this together." These words, can sound like empty rhetoric unless actions affirm the value of community. In the pre-pandemic world, it was possible - if but barely - to imagine that all, or most, members of the campus community had access to adequate resources, but under our current circumstances we must acknowledge not only are resources distributed unequally, but societal determinants and health disparities are a burden many of our students endure. Instructors must empathize with the situations our students find themselves in and realize that life is not as neat as it was on the well-manicured lawns of our campuses.

The COVID-19 pandemic is forcing us as educators to confront the fact that there are stark disparities of access to resources. When campuses were shuttered in response to the pandemic, many students lost access to food, housing, healthcare, tutorial services, libraries, computer labs, wet-labs, support groups, study space, high speed internet, specialized software, and like-minded thinkers. Our students come from every corner of the world and represent every coast here in the U.S. Their location is just as different as the types of circumstances from which they originate. Education is for all; and the university is a community of teaching and learning in which we all belong. Making the presumption that students have access to the same research rich environment and tools for remote instruction is an example of a false assumption.

\section{The Environment of the Student}

The survival of any organism is dependent on favorable factors, both internal and external. When homeostasis either internal or external is not achieved the organism cannot survive. In some cases, the presence of a negative factor (COVID-19, for example) can disrupt an organisms equilibrium directly. In other cases, the presence of a negative factor can disrupt other parts of an environment, making it toxic for an organism, ultimately harming it. COVID-19 has done both. It is simultaneous directly causing individual students to get sick, heightening mental health issues, and causing many available services often available to students on campus to be remote, more difficult to access, or completely inaccessible. These negative disruptions can affect a student's achievement by impeding their ability to process, comprehend and critically think about the information.

\section{Health Services}

One factor being impacted by the pandemic includes mental, physical and emotional health issues. When the students are on campus, they may have access to various mental health supports including counseling support groups and low-cost medications. Some students have an on-campus health insurance provider. Now that the university has switched to remote education the student's ability to use their health insurance, obtain necessary medications may be disrupted or in total disarray. Rather than blame students for their situations or try to "fix a damaged" student, we should be employing a trauma-informed approach that focuses more on the inequities within the system.

When considering our students' ability to thrive we must remember that they are organisms, and they too need a healthy internal environment. Therefore, we must bear in mind that their health may have been sustained due in large part to the availability of on-campus services. COVID-19 is scary and anxiety inducing even for the most composed and well-resourced student. For low income students, this is possibly a 
point where they could fall through the cracks of the education and healthcare system. It is incumbent upon instructors to be conscious of their voices in the virtual breakout rooms and their words in the chat for signs of excessive worry and distress. We cannot make up for lacking access to healthcare, but we can provide the support students need to survive a significant threat to their physical, mental and emotion well-being.

\section{Disability Services}

At this point most of the university offices are operating remotely and have adapted to their new methods of delivering services. This is also true for the office of disability services, the arm of the university charged with providing appropriate accommodations for students with a disability. The disability services may have adopted a modified program. Services that were once available to students may not be available in the same manner as they were when on campus. The COVID-19 crisis could cause two separate issues. One, students currently receiving accommodations may be having difficulty adapting to the modified delivery of disability service. Two, because the circumstances have changed rapidly in a drastic manner, this could trigger additional students to need services. Getting evaluated remotely may be difficult but, again instructors should remind students that if they need additional help or resources to reach out to the appropriate office.

Even though classes are being delivered through remote instruction, they should continue to be welcoming and accessible and for all enrolled. While many instructors are not experts in providing disability services, all instructors are capable of using universal design for learning strategies. For example, providing extra time on assignments and exams, finding multiple ways for students to access course materials (text, audio, video, etc.), and being provided clear checklists or descriptions for all assignments. In many cases, these are already common practices; however, it is more important than ever to ensure students are being provided with the supports they need to learn best.

\section{Food Insecurity}

Food insecurity is a consistent issue for many Americans including college students (Payne-Sturges, 2018). In recent years, in order to assist off-campus students encountering issues with hunger, many universities have installed food pantries or other auxiliary services to help meet these needs. Yet despite these additional efforts, some university food pantries cannot keep up with demand and some students remain food insecure. According to recent reports (Woods, 2017, Payne, 2018) and the American Association of Colleges and Universities (AAC\&U, 2017), food-insecure students were at increased risk of being housing insecure as well, in fact, 64 percent experienced housing insecurity, while 15 percent reported homelessness. Maslow's Hierarchy of Needs (physiological, safety, love and belonging, esteem, and self-actualization) matters in this case (Maslow, 1943): If a student's basic need are not met, they are unlikely to learn effectively.

While we believe universities should be attempting to provide meals to food insecure students, we also recognize the large undertaking that would require. Therefore, as instructors, we can realize that students are facing challenges that go beyond our course work. Allowing flexibility, wherever possible, can help students who are experiencing any number of challenges, find ways to survive, and learn. We may not know all the details of our students lives, nor should we; nevertheless, we must accommodate in ways that are uncompromising in a commitment to equity during this time, and as we move into a post-pandemic society.

\section{Housing}

One must not be naïve about the disparities and circumstances that some of our students have experienced. There is a segment of our student population who were homeless, foster children, or estranged from family because of issues related to poverty, abuse or gender/identity status before they ever arrived at school. Returning to a home that is unwelcoming, dysfunctional or abusive can have adverse consequences. We must accept the fact that some of our students are among the most vulnerable populations. According to a 2019 report on college level insecurity Goldrick-Rab and colleagues found that 18 percent of students attending two-year colleges, and 14 percent of those attending four-year institutions were homeless (Goldrick-Rab et al., 2019). In the U.S. 12 percent of two-year students and 9 percent of four-year students are completely homeless (Mendoza, 2018). This is particularly difficult during the COVID-19 pandemic. Students have not 
been allowed to reside on campus since early March. Theoretically, they went home, but what happens when there is no home? How is keeping up with course material balanced when the students are residing at a shelter or in their car? Former foster children are a particularly vulnerable demographic. They may have aged out of foster care and immediately moved into the universities on-campus housing. In this case there is no home to go to, the dorm was their home. Even if they are permitted to stay, they are isolated and separated from their community on campus. Additionally, they may be stranded on a campus that no longer provides meals and other services they need to live.

For others, homelessness can evolve into both a physical and emotional issue. When it comes to LGBTQ students depending on the dynamics of their parental home it is not uncommon for them to find themselves unwelcome into their family home after coming out. This is an especially difficult predicament because often the student now has an emotional struggle in addition to being homeless. In order to return home and avoid being homeless LGBTQ students are often asked to disassociate with who they are in order to conform to the rules of the house.

Now more than ever it is possible for students to not have a home or a country. There is a population of students who are being educated while in exile, in asylum or for other safety reasons cannot return to their home country. Such issues can be further complicated by questions about being a non-citizen or a DACA student. The completion of much of that documentation is by campus personnel. Due to language barriers facilitating the completion of such documentation remotely can become more difficult. Because of their citizenship status these students may not be eligible for the various federal public assistance programs that were put in place as a safety net for individuals in this position.

\section{Availability [?] Access}

There is no guarantee of internet access, stable Wi-Fi or bandwidth availability. As instructors that thrive off seeing the faces of students in class and feel affirmed by the eye contact and head nodding, blank screens with names can feel cold and detached. There is a worry that the student is disengaged; we have to move beyond our feelings though. This is not an indictment on one's ability to teach or deliver appropriate education, but we must consider the countless issues that affect whether a student is available to be visible online or not. In seeing the students' names there we must trust that they are in attendance. The fact of the matter is this is not the ecosystem campus was, where things were all equal. Some students may be accessing the class from their phone while sitting in the Walmart parking lot because they have exhausted their data allotment. Other students may be accessing the class from the bathroom of their house because that is the only quiet spot. Some students may be accessing class from standing on the street in front of a store because of the Wi-Fi accessibility. While other students may live in a mixed citizenship status home and be fearful of outsiders seeing their undocumented family members.

With students of all ages and parents all working from home the Wi-Fi is stretched to maximum capacity. The bandwidth may be low because there are many users. Purchasing additional bandwidth can be a socioeconomic issue. Countless families may not have funds to increase their internet services. Another issue is the different time zones. Again when everyone was on campus this wasn't an issue, but some of our students may be accessing our classes from around the world or on the other side of the United States. There is also a geographic issue, the internet is often available to rural students, but it may not be high speed. Any effort to increase bandwidth, speed or purchase additional devices becomes an issue of financial ability.

\section{The Niche}

In our higher education ecosystem, we all play a role. Instructors teach the course. Students learn and demonstrate their knowledge. We are not naive enough to think that instructors and students are only teachers and learners, however; within the neat confines of courses, it is easy to frame each other in this way. Under the most ideal circumstances, students bring their life experiences with them, as do instructors. Classrooms are not vacuums, but rather conduits for the discourses, ideologies, and ways of being that exist in our society. However, with the advent of the pandemic, roles are being blurred. Students and instructors are having to embody multiple roles at once, as they always did, but some roles are now being heightened 
more than others due to the pandemic.

\section{Joblessness and Depressed /Uncertain Economics}

The COVID-19 pandemic has brought about unimaginable economic damage. Currently, more than 41 million U.S. citizens have filed for unemployment since March, and at the last benchmark of April, 2020 14.7 percent its highest since the Great Depression. Unemployment is one of the greatest predictors of homelessness, food insecurity, physical and verbal abuse, and poor healthcare. It cannot be ignored that many of our students are living with newly unemployed parents and therefore had to take on a job of their own to supplement the lost income. Their former role as a student must come after providing for themselves and family.

\section{Unpaid Labor}

For many being at home entails additional responsibilities that normally do not coexist with school. Similar to women faculty, women students often find themselves assuming the greater share of domestic and caregiving responsibilities. A recent article in the journal Nature describes the imbalanced consequences of the COVID19 pandemic in women's academic productivity (Minello, 2020). When students go home, they return to the life that they would have before they were students. This is not business as usual some of those students came from circumstances where they have great family responsibility. The children of essential workers and first responders find themselves caring for younger siblings, the elderly relatives or the sick. Not only is this emotionally draining, but good caregiving is time consuming and physically demanding. In other cases, the student or a relative may be immunocompromised or have other comorbidities that put them at high risk. For the students whose parents are essential workers or first responders there is the consistent worry that these individuals who are doing the work to keep the rest of us safe and healthy may themselves be in harm's way or become ill because of their profession.

Depending on the severity, all the previously mentioned circumstances (untreated mental illness, anxiety, food insecurity, homelessness, physical and mental abuse, racial discrimination, poverty) can be traumatic to students. Employing the principles of trauma-informed teaching can help students to less susceptible to their problematic circumstances (Carello, 2015). Trauma-informed teaching centers around five fundamental principles a) ensuring safety, b) establishing trustworthiness, c) maximizing choice, d) maximizing collaboration, and d) prioritizing empowerment. These elements can be integrated into online and/or face-to-face teaching to promote a more inclusive environment for all students.

\section{The Promise Land}

\section{Campus Resources}

Working on campus often involves the use of innovative and new technology and software to which students have access while on campus. These campus equipment and software cannot be accessed from cell phones. In order to achieve success with distance education, the following course materials are necessary: (1) a laptop/cell phone with video capabilities; (2) eBook; and (3) an online homework system. Purchasing academic supplies can be difficult for many students and their families due to the exorbitant prices of tuition, books, computers, and subscriptions to wi-fi. It would be unreasonable to expect students to purchase additional technology or software outside of these course material requirements. If a student does not have a laptop and attends a university or college that has a loaner laptop system in place (where students can rent a laptop after completing a contract), then this would be a viable option. However, some institutions do not have such a loaner system currently in place. It is imperative for instructors to be mindful that everyone, students and faculty alike, are doing their best with the resources available.

\section{Conclusion}

The educational system has been in crisis for a long time, and the COVID-19 pandemic turned a magnifying glass on the societal determinants that cause educational inequities. At this point no person or institution is unaffected by the epidemic of educational inequality. Instructors, deans, provosts, and presidents are 
wrestling with these issues is because no sustainable long-term plan has been implemented more broadly by our government or other agencies. Colleges and universities educate the nations' students, whomever they are, no matter where they are from. Being aware of some of the difficult circumstances that students facing can assist us in selecting best teaching practices for increased equity and inclusion. Small changes in our teaching practices can have large learning implications over time. Though our one class will not change the entire educational system, we do have the power to lead by example, starting right where we are, one student at a time knowing that the circumstances of one's education matter. Teaching is our superpower. Starting now we can make the legacy of the 2020 pandemics aftermath a more equitable and inclusive system for teaching and learning in which all organisms thrive and flourish to their greatest potential.

\section{Hosted file}

COVID Ecology Figures.pptx available at https://authorea.com/users/334414/articles/460386an-ecosystem-of-equity-in-the-era-of-covid-19-considerations-for-creating-inclusiveteaching-and-learning-environments 